\title{
Analyzing key performance indicators of e-commerce using balanced scorecard
}

\author{
Seyed Kamal Chaharsooghi*, Nasrin Beigzadeh and Arman Sajedinejad
}

Department of Industrial Engineering, Tarbiat Modares University, Tehran, Iran

\begin{tabular}{|c|c|}
\hline CH RON I C LE & A B S T RA C T \\
\hline $\begin{array}{l}\text { Article history: } \\
\text { Received October 28, } 2015 \\
\text { Received in revised format } \\
\text { November } 28,2015 \\
\text { Accepted December } 29,2015 \\
\text { Available online } \\
\text { December } 30,2015 \\
\text { Keywords: } \\
\text { E-commerce } \\
\text { Performance evaluation } \\
\text { Balanced scorecard } \\
\text { Key performance indicators } \\
\text { Iranian business web sites }\end{array}$ & $\begin{array}{l}\text { E-commerce as one of the most significant aspects of innovation in business processes is what } \\
\text { takes place in companies across the world. The gap between information and communications } \\
\text { technology and e-business application is called the digital divide. It is necessary to understand } \\
\text { the reasons for the failure of commercial sites. Here the objective is to assess the commercial } \\
\text { sites of Iran. Different methods are adopted to evaluate sites and electronic stores. The balanced } \\
\text { scorecard is a rarely adopted method of concern to evaluate these sites in Iran. The survey } \\
\text { methodology and Delphi technique are applied in building the research tools, which led to the } \\
\text { development of a questionnaire. Through applying the BSC approach, the numbers of indicators } \\
\text { in each of the four perspectives of BSC were identified. The DEMATEL technique is applied } \\
\text { to determine the importance of different perspectives and to identify the causal correlations } \\
\text { among the four perspectives. The results generated by SMART PLS graphics, the Structural } \\
\text { Equation Modeling software, confirm the adequacy of this proposed model for websites. The } \\
\text { findings here indicate that the growth and learning perspective have the greatest impact on the } \\
\text { other perspectives while the other perspectives mostly affect the financial perspective. }\end{array}$ \\
\hline
\end{tabular}

\section{Introduction}

The competitive conditions of day-to-day activities require that the investment in the system be purposeful and contributive to the organizational advances in value product and gain competitive advantage. Determining the strategic objectives and, in particular, the evaluation of the organizational performance in different periods can be a good guideline for managers to deploy an appropriate management systems become aware of the current state as far as achieving the ultimate objective, namely continuous improvement is concerned. Performance evaluation, is the process through which the functionality of the organization's resources, the staff performance is reviewed and evaluated on a periodic and formal basis. In this process the objective is to evaluate and promote the performance of the organization.

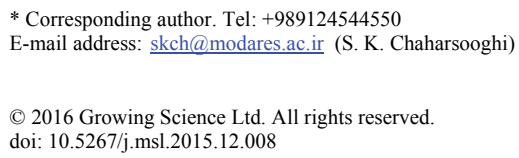


The major problem facing the traditional systems, which are primarily based on accounting indicators, is the inability of these indicators to contribute to the strategic issues when organizational performance is being surveyed. The new performance evaluation systems, such as the balanced scorecard model are designed to conform to the new environmental conditions. Performance evaluation models are the basis for assessing and improving the organizations' management systems. In Iran, the universities' websites and databases are usually assessed on the e-commerce and Internet stores. Many available studies focus on how to examine the technical condition of the Website, check the websites' position in search engines; while discussing on the website layout and graphics analysis, the analysis of the content of the website and the extent of its compliance with the objectives of the site. Finally a few solutions are provided to improve the graphics of the web sites to attract more audience, refine the information architecture approach, improve the speed of displaying the website and improve the performance of web security in order to reduce the chances of Internet attacks.

In Iran, most evaluating criteria of the webs include content, structure and visual design, functionality, interactivity, and other performance measures, used in the balanced scorecard, which is rarely applied in the studies. This study is concerned with identifying the key performance indicators in e-commerce and determining the causal correlations among the indicators of different perspectives of the balanced scorecard. Based on the available statistics, about 30 thousand Internet stores are active in Iran. The financial transactions of Internet sites and commercial areas are announced, insignificant figure, namely about 3 billion and from every 5 Iranian commercial sites, three sites fail. This fact makes the urgency of this issue apparent; therefore, performance evaluation and realization of the causes of this failure in Iranian websites becomes necessary which calls for offering solutions for its improvement.

The global network on the web is able to play an important role in various application areas such as trade, education, and industry. In the recent years, the fact that the e-commerce will bring member companies big profits is an indisputable fact. One of the most important issues, a major concern, among the managers and operators of websites is the subject of evaluation of web sites. In Iran, the balanced scorecard evaluation method was rarely considered in its virtual sense; but recently investigation and research on e-commerce is of serious concern.

Applying the balanced scorecard method to identify and analyze the key performance indicators in ecommerce and virtual stores is one of the new aspects that will be addressed in this study. The innovative aspect of this study and the difference between this and previous studies is in the process through which the virtual stores were being evaluated through the known methods. Here, for the first time the combination of BSC-DEMATEL model is adopted to analyze the key performance indicators in the commercial websites of Iran. With the fast growth of the Internet, various forms of e-commerce have become subject to overhaul. Manufacturers of various products have created web shops to improve the sales chances. As the techniques and approaches of running a web shop differ, the assessment of performance of web shops has become complicated. So, by the multi-criteria decision making method, this study offers a systematic and consolidated model for evaluation of web shops' performance.

\section{Literature Review}

Performance measurement can be defined as the process of quantifying the efficiency and effectiveness of activities carried out (Kaplan \& Norton, 1992). Performance evaluation is a systematic and periodic process that evaluates an individual employee's job performance and productivity in relation to certain pre-set up standards and organizational objectives (Manasa \& Reddy, 2009). Over the years many methods have been adopted in analyzing the system performance like ratio analysis, total production analysis, regression analysis, Delphi analysis, balanced scorecard (BSC), analytic hierarchical process (AHP), data envelopment analysis (DEA), Dematel technique and Structural equation modeling. Adopting any of these methods depends on the situation and the type of the organization. 
As a new approach, the balanced scorecard combines the indicators of financial performance and shortterm business with non-financial indicators derived from the organization's vision and strategy (Meng \& Pan, 2012). The BSC is basically focused on the two main problems of modern business organizations: effective performance measurement and assessment of the success in implementation strategies (Grigoroudis et al., 2012). The various aspects of this model, addresses four basic questions: 1. Financial aspect: what is our vision of the shareholders? 2. Customer aspect: how is the customer's vision for us? 3. Internal Processes aspect: what activities can we do well? 4. Learning and Growth aspect: how can we take steps toward continuous improvement? (Kaplan \& Norton, 1993). To evaluate the systems, it is necessary to identify the key performance indicators. The KPIs are widely embraced by enterprises as a performance assessment tool.

In the other study, researchers propose a new combined method of balanced scorecard, path analysis, evolutionary game theory and cooperative game theory for strategic planning. As a case study the implementation of this proposed method is introduced for a food producer and the findings are analyzed (Eskafi et al., 2015). The key performance indicators (KPIs) are the cornerstones of the performance system, which convert the strategic targets of an organization into long-term objectives. The establishment of clear and possible KPIs contributes to better performance management. The KPIs are the benchmarked metrics in evaluating performance. In establishing such metrics, it is vital to realize the desired outcome for the function of each section (Tsai \& Cheng, 2012). E-commerce is defined as the trade and exchange of products, services, or information through the Internet (Turban et al., 1999). In most of the studies the e-commerce web sites are evaluated according to the following five dimensions: features of the site, website navigation, site content, reliability and site technical (Merwe \& Bekker, 2003).

Prosperity of e-commerce in majority of B2B sites depends on their ability to manage data and converting information into them. Implementation of e-commerce in big companies requires compatibility and coordination among all their components. The researchers modeled the impact of ecommerce implementation on the changing correlations between buyers and sellers (Alderete, 2010). Websites with low quality have the disadvantage of attracting, satisfying and retaining customers. Website quality influences its financial performance, the customers' purchase intention in particular. Chen et al. (2013) in a study on commercial websites in Thailand and Taiwan, reported that the indicator "attitudes towards the site" is considered as an indicator of effectiveness. The main objective of their study was to combine the concepts of quality and user satisfaction in the success of a web site. The second objective of their study was to investigate the cultural influences of websites on the users. They revealed that the users who tend to buy from the sites differ in different countries. For example, shopping culture and effects of websites in Canada and Europe are not the same. Therefore, components, and indicators to assess websites also vary. The proposed model regarding the success of the web sites in the two countries under study was put to test (Chen et al., 2013). Olsina and Gustavo (2001) offered a quantitative evaluation method for evaluation of the quality of Web sites and Web application programs (Web QEM). After reviewing this procedure and its supporting tools, they discussed about a case study in electronic commerce. This method is applicable in a systematic review of characteristics affecting the product quality. They showed that partial or total assessment areas and key indicators of quality can help investors understand and improve product evaluation (Olsina \& Gustavo, 2001).

Beranek and Knizek (2012) offered a computational model of trust to the commercial sites' online auction vendors in the Czech Republic. This model applies all the relevant information about the user behavior in online auctions, which is based on the assessment of user reactions after the transactions. In a case study on Czech online auction Aukro the accuracy of this offered model is confirmed (Beranek \& Knizek, 2012). In another study, Storto (2013) presented an integrative framework based on data envelopment analysis (DEA) for measuring the efficiency of e-commerce web sites from a user view. This framework is inspired by the information processing theories, concepts of information and 
efficiency as a benchmark for performance and quality of the websites. In general, nine variables are measured in three sets of user experience, the availability of the site and the structure. This framework is implemented in the comparison of $52 \mathrm{e}$-commerce websites that offer products related to information technology and media. Stepwise regression is conducted to evaluate the costs and benefits in order to become a known website. This framework is capable to model web interaction with the user as a black box with a set of functions for various operations (Storto, 2013).

In a study, conducted by Alam and Yasin (2010) on online airline ticket sales in Malaysia's sales sites, the researchers found that the online brand trust plays an important role in increasing transaction of the sites. Variables such as security, privacy, word-of mouth, good online experience, quality information and brand reputation are known as significant factors, influencing online brand trust (Alam \& Yasin, 2010). Many studies are conducted in the field of quality assessment of service provider's web sites. Most evaluations are concentrated on the supply side. To solve this problem by a simple assessment tool, the IPA, customer satisfaction is evaluated and prioritized through improvement factors. Finally useful recommendations are offered to policy makers and planners for the growth of e-government (Wong et al., 2011). In a study Muhtaseb et al. (2012) in Greece, the factors affecting the efficiency and functionality of e-commerce websites together with users' attitudes, focusing on eight e-tourism websites were identified. The researchers applied a multi-criteria satisfaction analysis approach for evaluating the customer satisfaction. The obtained results were applied in e-commerce websites' design (Muhtaseb et al., 2012). To confirm the proposed model in most studies the structural equation model can be applied. Structural equation modeling (SEM) is a statistical methodology that requires a confirmatory approach to the analysis of a structural theory (Byrne, 2010). The SEM conveys two significant facets of the approach: (a) the alternate process is indicated by a series of structural equations (the regression) and (b) these structural correlations can be modeled in a visual manner to reveal clearer concept of the theory being analyzed (Wong et al., 2011). The first generation of structural equation is Covariance-Base and second generation is Component-Base. The three software LISRE, AMOS, and EQS belong to Covariance-Base, which require a great sample size. The main objective of this method is verifying the proposed model. The PLS software belong to Component-Base. Component-based approach, later renamed as Partial Least Squares was developed in 1974. The most important advantage of the PLS is its ability to analyze data with low volume (Hulland, 1999).

\section{Research methodology and design}

The method adopted in this study is descriptive. The instrument used in this study, is the combination of field survey methods (questionnaires and interviews) and the library method.

\subsection{Research design}

Likert scale is used for scaling responses and study variables in the questionnaire. The flowchart of this study is shown in Fig. 1. The Delphi method is a technique used in-group communication. This approach allows experts and specialists to trade systematically even if there exists a complex problem or mission. The basis of this method is simple: to gather the opinions of experts a series of questionnaires are sent to their mail or e-mail panel. This method is considered as an effective method to reach consensus and to forecast future events while being a good tool to collect the opinions of experts from different locations; a structured process of the group communication that helps to achieve consensus among experts. When a dispute arises the members of the group provide individual feedback, and then pursue and modify their opinions until consensus is reached (Tsai \& Cheng, 2012). The Delphi method process is shown in Fig. 2. 
1.Reviews of different methods of performance evaluation, in particular BSC and overview of E-Commerce

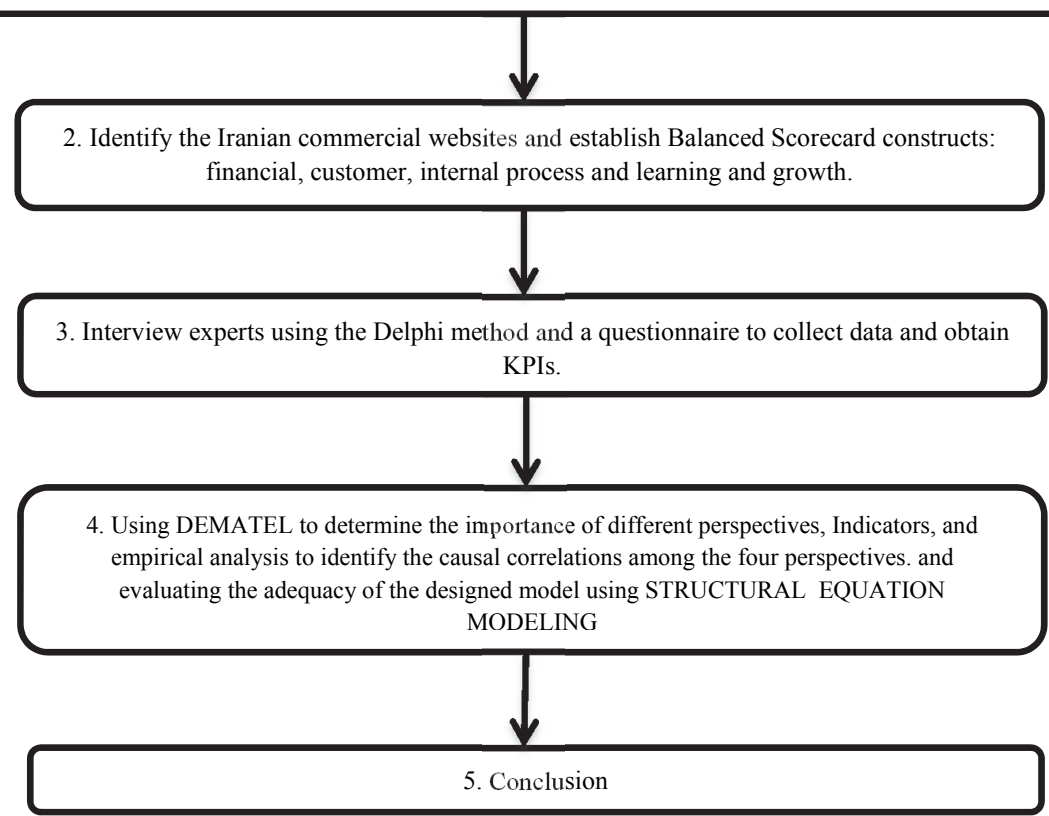

Fig. 1. Study flow chart
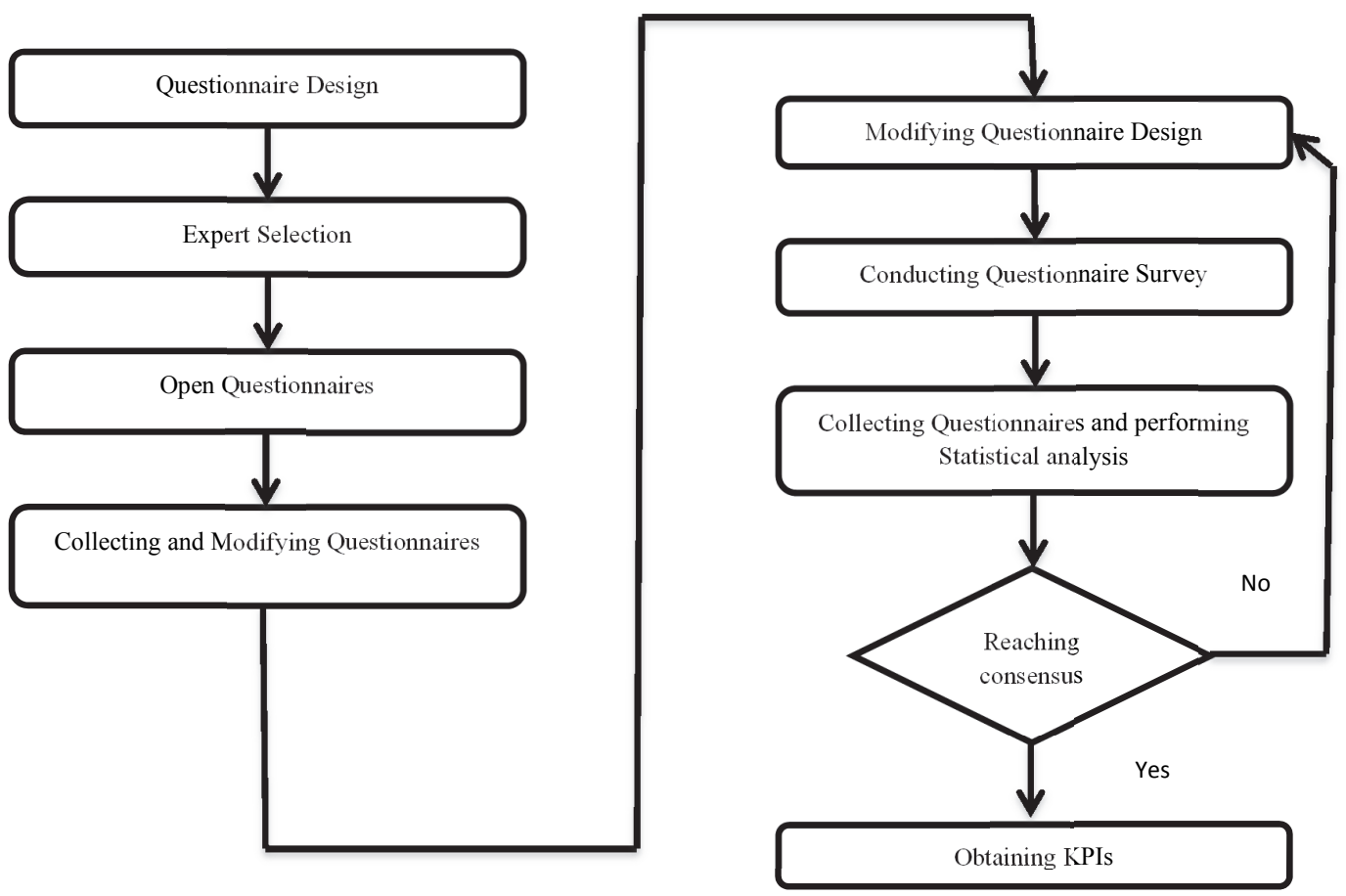

Fig. 2. The Delphi method process (Tsai \& Cheng, 2012)

By adopting the Delphi method, along with the questionnaire, the key performance indicators of the organization are identified. 


\subsection{The statistical sample and the tools}

The number of commercial websites in Iran is numerous. Of course, most of them have low financial transactions. In this study, in terms of products and services provided on the site, all business websites in Iran are considered. The cooperation request and the initial questionnaire are sent to 120 webmasters of active sites. Contact with the sample group took place through face-to-face and telephone interviews, and sending emails. Most of the reviewed websites are rated high in various titles on the Web Festival in Iran in 2013, which offer more than 100 different products. The statistical sample in this research includes experts and professionals in the fields of information technology and e-commerce. Consisting of two categories: (a) academic experts, 10 university professors, and (b) professional experts who are managers of 17 active commercial websites in Iran. In this study open and closed questionnaires are used to collect data from experts. Experts confirm the validity of the questionnaire. The reliability of the questionnaires is calculated through Cronbach's alpha and more than 0.7 is obtained for each of the four balanced scorecard perspectives, indicating a desirable reliability.

\subsection{DEMATEL Technic}

The DEMATEL technique, is one of the various methods of decision-making based on paired comparisons, with the advantage of expert judgment in extracting factors in a system and their systematic structuring generates the hierarchical structure of the factors in the system by applying the principles of graph theory. The steps and procedures in the factor analysis and DEMATEL analysis are briefly outlined as follows (Chen, 2012; Chen et al., 2011; Chen et al., 2013; Hsu, 2012; Mehregan, 2012).

1. In this method through one of the ways of creating idea in the experts, the brainstorming, the Delphi or a conference, a list of available and effective factors and criteria of the issue, should be extracted according to the view of the group of participating experts.

2. From the extracted factors in the previous step, a survey matrix is prepared, that the rows and columns of which represents the obtained factors and criteria. The experts are asked to determine the initial matrix (unfilled) with paired comparison and effect of each measure on the other measures. The Likertscale is often used, ranging from 0 to 4 . The impact levels are categorized as: no impact ( 0 point), low impact ( 1 point), moderate impact ( 2 points), high impact (3 points), and severe impact (4 points).

3. Matrices obtained from the second step are collected and the presence or lack of a correlation between two factors is determined, with the comments of the majority of experts.

4. In this study, 27 experts and four elements are dealt with. Each expert is asked: "To what extent does factor I affect factor $\mathrm{j}$ ?" The binary relations and the effectiveness of each relation are investigated and the average matrix is determined. Here a $4 \times 4$ matrix can be generated upon the questionnaires filled by the experts.

5. According to the third and fourth steps, the matrix $Z$ that indicates the severity of the effect of governing direct relations existing in the system is determined.

6. In this step the normalized initial direct-relation matrix is calculated. Matrix $Z$ is turned into a normalized initial direct-relation matrix, called matrix $X$ presents as the following equations

$$
\begin{aligned}
& X=s . Z \\
& \mathrm{~s}=\frac{1}{\operatorname{Max} 1 \leq i \leq n \sum_{j=1}^{n} z_{i i}} \quad i, j=1,2, \ldots \ldots n
\end{aligned}
$$


7. With a standardized correlation matrix (X), the matrix $\mathrm{T}$ which represents the direct and indirect relationships existing in the system, can be generated through the following equation

$$
T=X(I-X)^{-1}
$$

where, I indicate the identity matrix

$$
\begin{aligned}
& T=X+X^{2}+\ldots+X^{t}=\frac{X\left(I-X^{t}\right)}{(I-X)} \\
& T=\frac{X}{I-X}=X(I-X)^{-1} \\
& \operatorname{Lim}_{t \rightarrow \infty} X^{t}=0
\end{aligned}
$$

8. The total correlation matrix can be obtained through a simple mathematical calculation. The total relation matrix, $\mathrm{T}$, consist of highly possible intensity of indirect correlations which is calculated through the following equations

$$
T=X^{2}+X^{3}+X^{4}+\ldots+X^{t}=X^{2}(I-X)^{-1} \quad \lim _{t \rightarrow \infty} X t=0
$$

9. The sum of values $\mathrm{D}$ and $\mathrm{R}$ are obtained by adding up values from every row and column of the direct/indirect relation matrix (T), respectively, as presented in Eq. (6). The D represents the direct or indirect impact level of a specific criterion on other criteria, and $\mathrm{R}$ represents the level one criterion affected by other criteria

$$
T=t_{i j}, \quad i, j=1,2, \ldots \ldots, n \quad R=\sum_{i=1}^{n} t i j \quad D=\sum_{j=1}^{n} t i j
$$

10. At last a causal diagram can be presented by plotting the coordinate values of each criterion into a scatter plot with the horizontal axis $(D+R)$ and the vertical axis (D-R).

\section{Research findings}

\subsection{Descriptive analysis of the data}

By using descriptive statistical methods such as frequency distribution tables, drawing the corresponding graphs and the demographic information on the questionnaires is evaluated. The measures of central tendency and deviation, such as the mean, standard deviation, median and mean standard error for each one of the indicators (Questions of Questionnaire) are calculated.

In order to save space in this article, only 4 charts, based on the average values of the indicators are presented at the end. In Figs. (6-9), the indicators identified in the four perspectives of the balanced scorecard for the evaluation of commercial websites in Iran, based on their mean scores, are shown according to the opinion of the experts. As the five-point Likert scale is used for the data analysis of questionnaires, the indicators with an average higher than 3 are accepted. The paired comparisons technique is applied in data analysis. The descriptive statistics are generated by Microsoft Excel and SPSS. The highest mean value of the indicators is assigned from the internal process perspective. A high mean value suggests that most of the experts placed great emphasis on "Transaction Safety and Assurance". The lowest average value also belongs to "Web personalization" from the customer perspective, showing a low emphasis on this perspective by the majority of the experts.

\subsection{Statistical analysis of data}

The experts are asked to indicate the influence of each correlation among the perspectives through the second part of the questionnaire. 


\subsubsection{Results of the DEMATEL technique}

By using the DIMATEL technique and calculating the arithmetic average of the experts' response to summarize their opinions, the direct and indirect correlation matrix of the key performance indicators is obtained and presented in Table 1.

Table 1

Direct/indirect correlation matrix of the KPIs

\begin{tabular}{ccccc}
\hline Notation & Financial & Customer & Internal process & Learning and growth \\
\hline Financial & 0 & 1.66 & 1.74 & 1.64 \\
Customer & 2.29 & 0 & 1.16 & 1.32 \\
Internal process & 1.78 & 1.97 & 0 & 1.83 \\
Learning and growth & 1.86 & 1.98 & 1.93 & 0 \\
\hline
\end{tabular}

Here, the DIMATEL method is adopted to investigate the effect of the initial ranking upon each other and their final rankings, which lead to a reduction in human error. To calculate (D+R) and (D-R), the $\mathrm{D}$ value and R-value are rearranged in the correlation matrix of the total criterion effect (direct / indirect) in Table 1. The total value of an index has an impact on the other index (D) and the full value of an index is affected by other index obtained by adding the values of rows and columns, respectively, from the direct/indirect relationship matrix that is presented in Table 1 . The $\mathrm{D}+\mathrm{R}$ represents the correlation intensity between one indicator and the others, and D - R represents how one indicator is affected by the other indicators as shown in Table 2 .

Table 2

Sums and differences of values from rows and columns

\begin{tabular}{lcccc}
\hline Notation & $\mathrm{D}$ & $\mathrm{R}$ & $\mathrm{D}+\mathrm{R}$ & $\mathrm{D}-\mathrm{R}$ \\
\hline Financial & 5.06 & 5.95 & 11.01 & -0.89 \\
Customer & 4.78 & 5.62 & 10.40 & -0.83 \\
Internal process & 5.69 & 4.84 & 10.54 & 0.85 \\
Learning and growth & 5.78 & 4.91 & 10.70 & 0.87 \\
\hline
\end{tabular}

\subsubsection{Offering the theoretical model}

The location of the elements in the possible hierarchy and the causal correlations among the four perspectives of the balanced scorecard with respect to the values obtained from the above matrix computation are shown in Fig. 3.

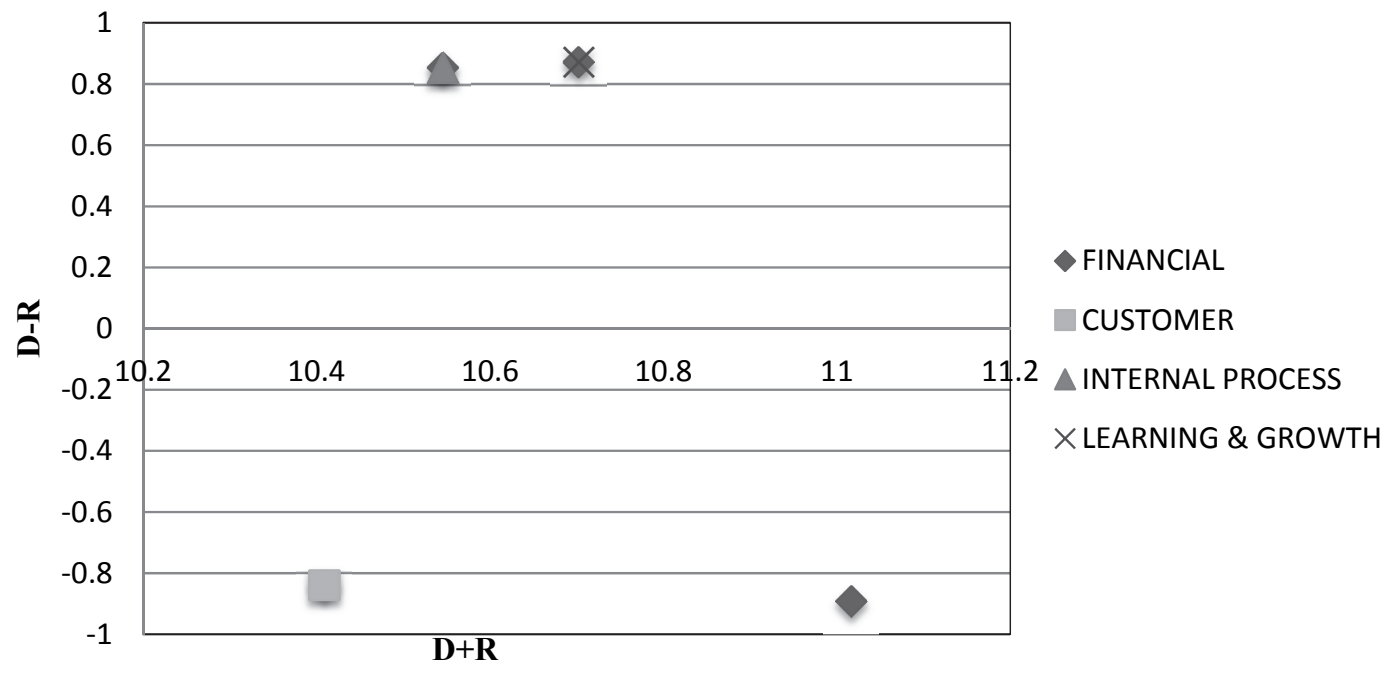

Fig. 3. Causal diagram of the KPIs 
The high value of $\mathrm{D}+\mathrm{R}$ factor suggests that one specific indicator has greater interaction with other system components; that is the more positive the $\mathrm{D}+\mathrm{R}$ is, the bigger is the level of influence on other components. The results obtained in this study indicate that the perspectives are ranked as Financial, Learning and Growth, Internal process and Customer in accordance with their importance from top to bottom, respectively. A great positive value of D-R, indicates that a certain index directly impacts other indicators, while a great, negative value suggests that certain index is affected by other indicators. Ranking the Learning and Growth perspective at the greatest positive value based on D-R indicates that this perspective is the most influenced on the others. The Financial perspective has the greatest negative value, suggesting that it is an important indicator in the way it is affected by others. Using these results and causal diagrams obtained from the DEMATEL technique, according to the calculated values of causal correlations in the matrix of direct and indirect key performance indicators as shown in Table 1, the perspectives' influence on one another is determined. A theoretical model for the mutual correlations among the four perspectives of the balanced scorecard is illustrated in Fig. 4.

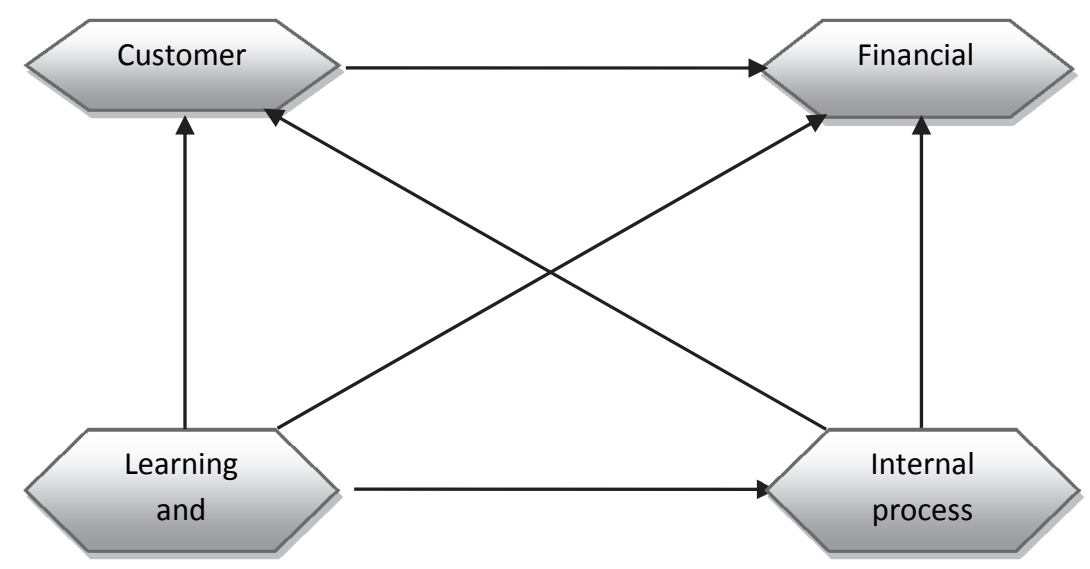

Fig. 4. A theoretical model of mutual correlations of four perspectives

\subsection{Testing the presented model here by Smart PLS, a structural equation modeling software}

Before analyzing the results, the accuracy of the model must be verified. The Conformity Factor Analysis is conducted to confirm the model. The present model information and relevant indicators and correlations among the perspectives are the Smart PLS software and the relevant outputs are listed as follows (Kline, 2010):

- If the factor loadings are less than 0.3 are considered to be a weak correlation, thus it is ignored.

- Factor loadings between 0.3 and 0.6 are acceptable and if are greater than 0.6, thus desirable.

- To investigate the significant correlation among the variables, t-test statistics or the $t$-value is applied.

- As the significant correlation is examined, at the error level of 0.05 , so if the observed factor loadings of the t-value tests are smaller than 1.96, there is no significant correlation.

- If $\mathrm{R}^{2}$ values are greater than 0.67 , the model is evaluated as very good, if about 0.33 , average and about 0.19 , is poor.

The t-value amounts are obtained, through bootstrapping. For this proposed model the t-value is higher than 1.96, indicating that the observed correlation is significant. Subsequently, by inserting the required info in the given software. The factor loading network is produced where the path coefficients or factor loadings for each indicator and perspective are demonstrated in Fig. 5. 


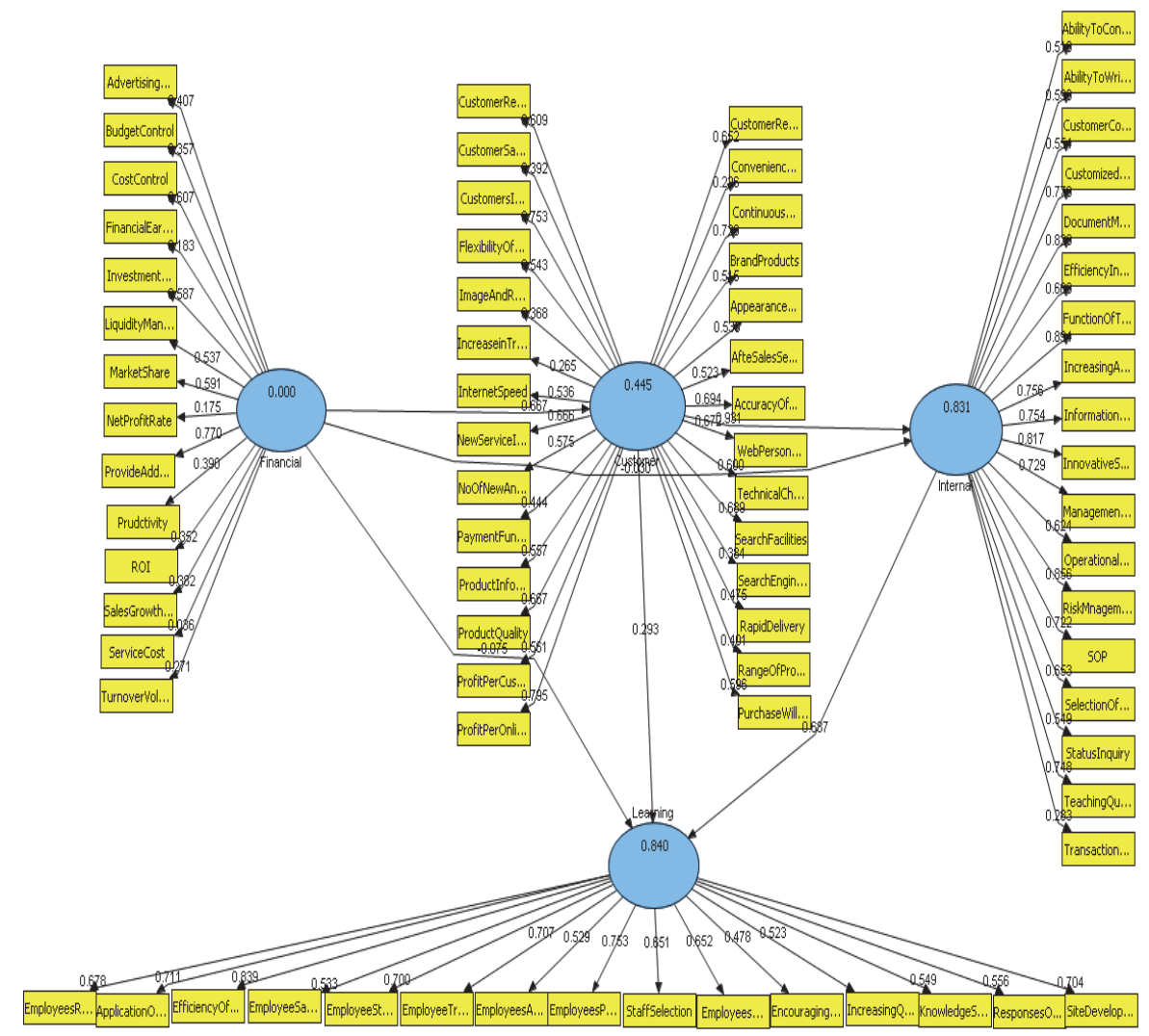

Fig. 5. A theoretical model is verified by the software

\subsubsection{Implementation model in Smart PLS software, the results}

In fig. 5 the factor loadings of the t-value tests are greater than 1.96, indicating good adequacy and fitness of the presented model. According to the data obtained from the software after implementation of Bootstrapping and is shown in table 3, all values become greater than 1.96, so the fitness and adequacy of the proposed model is evaluated very well.

Table 3

Amounts of t-value for the presented model

\begin{tabular}{cc}
\hline Influence of different perspectives & T-value \\
\hline Internal process $\rightarrow$ Customer & 22.16 \\
Learning and growth $\rightarrow$ Customer & 18.18 \\
Customer $\rightarrow$ Financial & 14.28 \\
Internal process $\rightarrow$ Financial & 9.05 \\
Learning and growth $\rightarrow$ Financial & 6.96 \\
Learning and growth $\rightarrow$ Internal process & 5.06 \\
\hline
\end{tabular}

After the implementation of the theoretical model, using Structural Equation Modeling in Smart PLS software, the indicators' impact coefficients are identified in the four perspectives of the Balanced Scorecard. As a result, according to the experts, all indicators of the "financial" and "Learning and Growth" perspectives are selected correctly, while changes in the "Internal processes" and "Customer" perspectives should be applied (Table 4). From the 75 obtained indicators, nine are transitioned from the assumed perspectives into a new perspective. 
Table 4

The results of changes in perspective of key performance indicators

\begin{tabular}{ccc}
\hline KPIs & Assumed Perspective & New Perspective \\
\hline Transaction safety and assurance & Internal process & Customer \\
Ability to write marketing proposals & Internal process & Learning \& growth \\
Status inquiry & Internal process & Customer \\
Customer complaint management & Internal process & Customer \\
Rapid delivery & Customer & Internal process \\
Profit per customer & Customer & Financial \\
Flexibility of service system & Customer & Internal process \\
Customer retention rate & Customer & Internal process \\
Search engine optimization & Customer & Learning \& growth \\
\hline
\end{tabular}

\section{Conclusions}

The results of the data analysis confirm the existence of causal correlations among the key performance indicators in the performance of a web shop. There are 14 indicators in the financial, 18 in the internal process, 28 in the customer and 15 in the learning and growth constructs. In terms of importance the Financial perspective is ranked the highest, followed by Learning and Growth, Internal process and Customer. The Learning and Growth perspective is the major construct impacting other constructs. The Learning and Growth perspective has the greatest impact on the Customer perspective, followed by Internal process and financial perspective. The Financial perspective was an important item affected by others. The Financial perspective is affected mostly by the Internal process followed by Customer and Learning and Growth perspective.

The findings indicate that for the success of a commercial web site or virtual store, the managers should concentrate on their internal standard operating procedures and should ensure the satisfaction of customers based on its operational processes, including the management of orders, product selection and representation, organizational innovation and after sales services. Indicators of the customer construct show that, websites and virtual store administrators should consider customers who tend to buy and guarantee their satisfaction level in order to enhance customer confidence. The online platform for e-commerce, should be user friendly, fast in delivery operations after the customer orders are placed with a proper after sales service. The severity of the correlation among the constructs of the various key performance indicators can be identified through a causal diagram. After obtaining the key performance indicators, the website administrators should collect, extract, share, publish, and adopt innovative methods for their application as core values of the organization and convert the mission of web shop into a management activities and daily tasks of the different departments.

Moreover, the key performance indicators can be applied as a communication channel for employees to understand the organization's overall strategy and to enhance their cooperation. Improving performance through key performance indicators for any website and virtual shop can be different and unique; therefore, the priority of the indicators should be determined based on operational programs of the organization or websites, customer needs and external changes and threats. An Internet service provider needs to strengthen management and operational models of its web shop and become familiar with the internet marketing tactics in order to earn more income and enhance the website competitiveness.

E-commerce is considered as the most innovative application in the Internet, being discussed in many developed countries in recent years. The original founders of the e-commerce were big companies with the objective to sell goods and services in global markets or create an extensive connection with suppliers. 
In this study, through a quantitative analysis and a comprehensive assessment, the key indicators of the e-commerce mechanism are found. The results obtained here can increase the operational capabilities of e-commerce in Iran and improve organizational performance while creating competitive advantages. The following major points can be considered in the revaluation of commercial sites:

1. Currently, there is no standard and accepted mechanism, to be administered to evaluate all kinds of business sites in Iran.

2. Holding competitions among portals and sub- portals at the national level, could be a dynamic force for public relations in updating their Web sites and portals and upgrading the level of services and information of these electronic systems.

3. Nowadays, almost all state apparatus of Iran and the vast majority of the companies of the private sector have a portal and web site, while the conducted surveys indicate that most of these portals are out dated.

4. Making the state of commercial web sites up to date by developing and improving the portals. In figures (6) to (9), the indicators identified in the four construct of the balanced scorecard for the evaluation of commercial web site in Iran based on their mean scores, are bar-charted according to the opinion of experts.

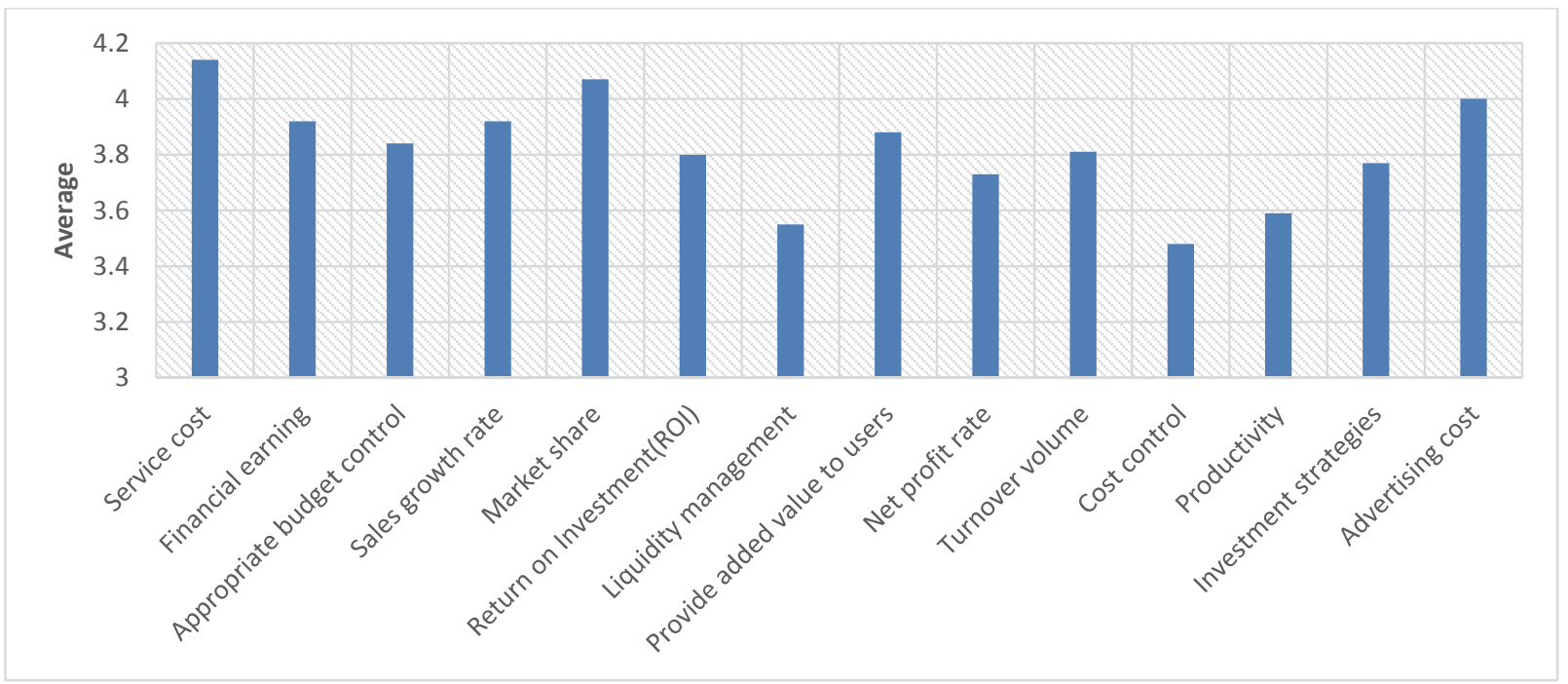

Fig. 6. Indicators of financial construct and their average

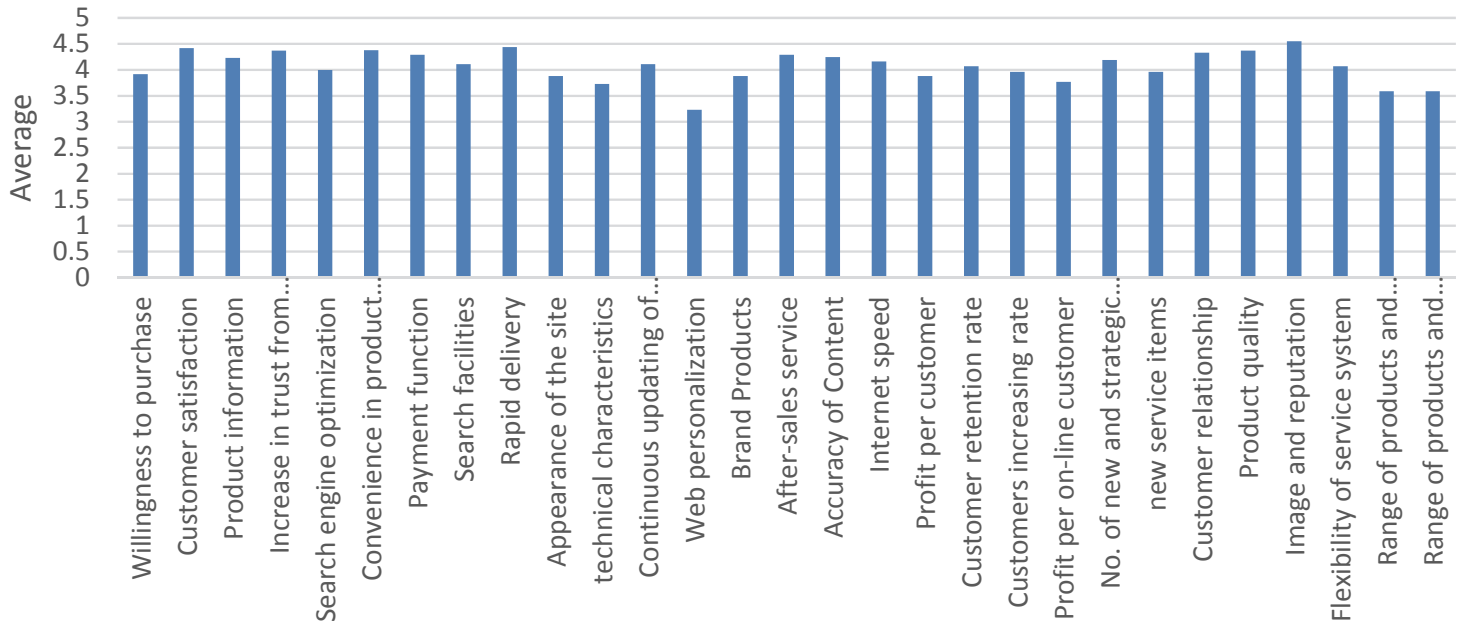

Fig. 7. Indicators of customer construct and their averages 


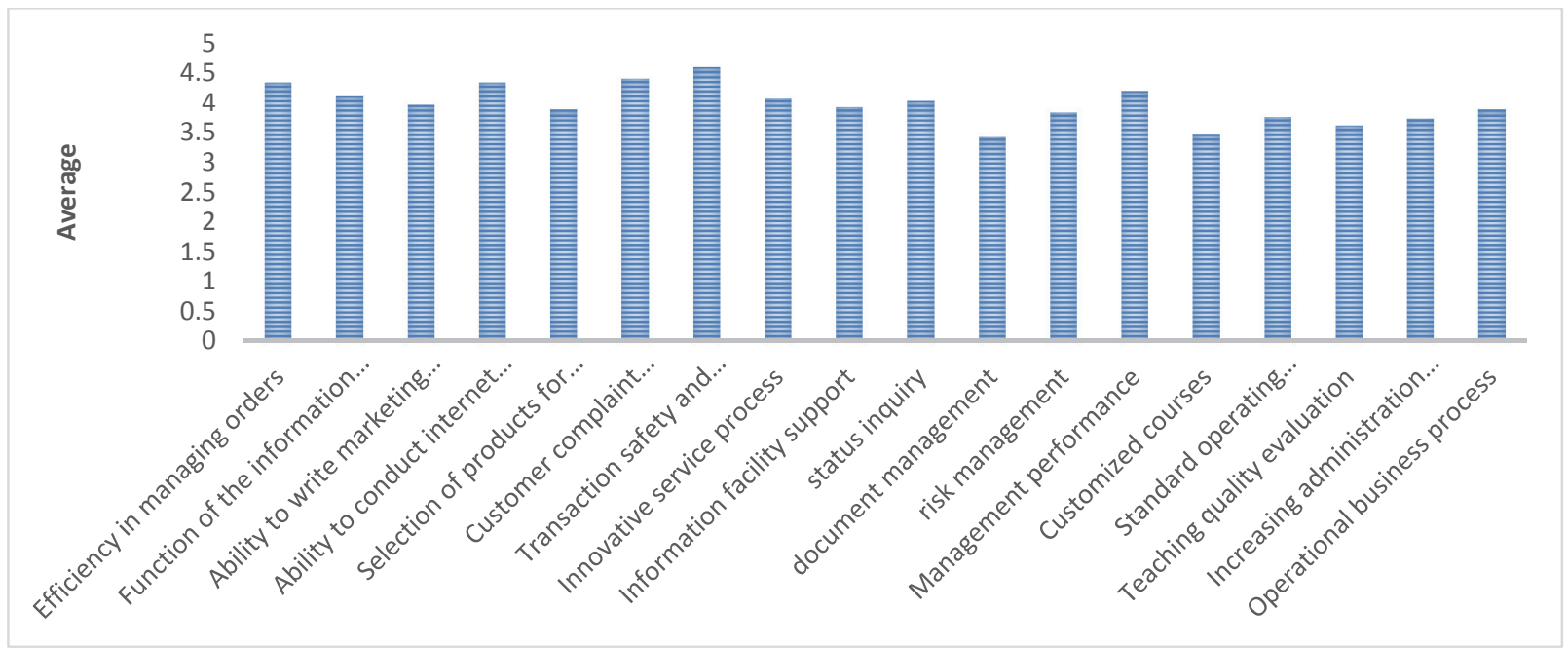

Fig. 8. Indicators of internal process construct and their averages

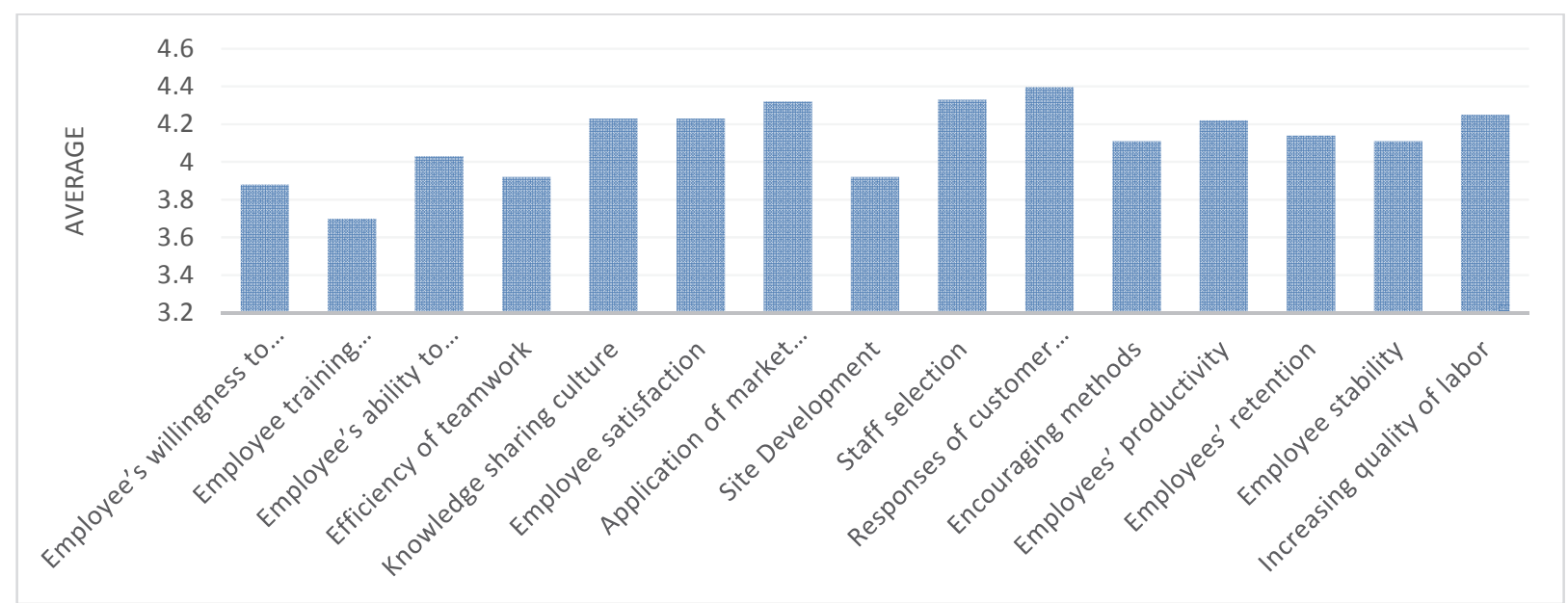

Fig. 9. Indicators of growth and learning construct and their averages

\section{References}

Alam, S. S., \& Yasin, N. M. (2010). What factors influence online brand trust: evidence from online tickets buyers in Malaysia. Journal of Theoretical and Applied Electronic Commerce Research Electronic Version, 5(3), 78-89.

Alderete, M. V. (2010). From traditional transactions to B2B: a contract theoretical analysis. Journal of Theoretical and Applied Electronic Commerce Research Electronic Version, 5(3), 17-26.

Beranek, L., \& Knizek, J. (2012). The usage of contextual discounting and opposition in determining the trustfulness of users in online auctions. Journal of Theoretical and Applied Electronic Commerce Research, Electronic Version, 7(1), 34-50.

Byrne, B. M. (2010). Structural equation modeling with AMOS: Basic Concepts, Applications, and Programming (2nd edition). Routledge Academy, New York.

Chen, C. A. (2012). Using DEMATEL method for medical tourism development in Taiwan. American Journal of Tourism Research, 1(1), 26-32.

Chen, F. H., Hsu, T. S., \& Tzeng, G. H. (2011). A balanced scorecard approach to establish a performance evaluation and relationship model for hot spring hotels based on a hybrid MCDM 
model combining DEMATEL and ANP. International Journal of Hospitality Management, 30(4), 908-932.

Chen, J. V., Rungruengsamrit, D., Rajkumar, T. M., \& Yen, D. C. (2013). Success of electronic commerce Web sites: A comparative study in two countries. Information \& management, 50(6), 344-355.

Hsu, C. C. (2012). Evaluation criteria for blog design and analysis of causal relationships using factor analysis and DEMATEL. Expert Systems with Applications, 39(1), 187-193.

Eskafi, S., Roghanian, E., \& Jafari-Eskandari, M. (2015). Designing a performance measurement system for supply chain using balanced scorecard, path analysis, cooperative game theory and 
evolutionary game theory: A Case Study. International Journal of Industrial Engineering Computations, 6(2), 157-172.

Grigoroudis, E., Orfanoudaki, E., \& Zopounidis, C. (2012). Strategic performance measurement in a healthcare organization: A multiple criteria approach based on the balanced scorecard. Omega, 40 (1), 104-119.

Hulland, J. (1999). Use of partial least squares (PLS) in strategic management research: A review of four recent studies. Strategic Management Journal, 20(2), 195-204.

Kaplan, R. S., \& Norton, D.P. (1992). The balanced scorecard: Measures that drive performance. Harvard Business Review, 70(1), 71-79.

Kaplan, R. S., \& Norton, D.P. (1993). Putting the balanced scorecard to work. Harvard Business Review, 134-142.

Kline R. B. (2010). Principles and Practice of Structural Equation Modeling. Series Editor's Note by Todd D. Little. The Guilford press, New York London.

Manasa, K. V. L., \& Reddy, N. (2009). Role of training in improving performance. The IUP Journal of Soft Skills, 3(3), 72-80.

Mehregan, M. R., Razavi, S. M., \& Akhavan Anvari, M. R. (2012). Identification and evaluation of strategic decisions in Gas industry using DEMATEL method. Iranian Journal of Management Studies (IJMS), 5(2), 49-65.

Meng, J., \& Pan, P. L. (2012). Using a balanced set of measures to focus on long-term competency in internal communication. Public Relations Review, 38(3), 484-490.

Van der Merwe, R., \& Bekker, J. (2003). A framework and methodology for evaluating e-commerce web sites. Internet Research, 13(5), 330-341.

Muhtaseb, R., Lakiotaki, K., \& Matsatsinis, N. (2012). Applying a multicriteria satisfaction analysis approach based on user preferences to rank usability attributes in e-tourism websites. Journal of theoretical and applied electronic commerce research, 7(3), 28-48.

Olsina, L., \& Gustavo, R. (2001). A quantities method for quality evaluation of web sites and applications. IEEE Multimedia Magazine, 32(4), 169-194.

lo Storto, C. (2013). Evaluating ecommerce websites cognitive efficiency: An integrative framework based on data envelopment analysis. Applied ergonomics, 44(6), 1004-1014.

Tsai, Y. C., \& Cheng, Y. T. (2012). Analyzing key performance indicators (KPIs) for E-commerce and Internet marketing of elderly products: A review.Archives of gerontology and geriatrics, 55(1), 126132.

Turban, E., Lee, J. King, D., \& Chung, H.M. (1999). Electronic Commerce: A Managerial Perspective. Prentice-Hall, New Jersey, USA, 1999.

Wong, K. L., Kuek, T. Y., \& Ong, S. F. (2011). A structural modeling (SEM) evaluation of the equation statistical adequacy of the strategic management model. African Journal of Business Management, 5 (15), 6591-6596.

Wong, M. S., Hideki N., \& George, P. (2011). The use of importance-performance analysis (IPA) in evaluating Japan's e-government services. Journal of Theoretical and Applied Electronic Commerce Research, Electronic Version, 6(2), 17-30.

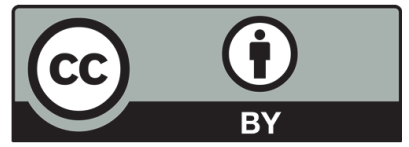

(C) 2016 by the authors; licensee Growing Science, Canada. This is an open access article distributed under the terms and conditions of the Creative Commons Attribution (CC-BY) license (http://creativecommons.org/licenses/by/4.0/). 